NOYICE

C.JPTIINS OF THIS REPORT ARE II LECIBI E os been repraduce broadest onssinle avail-
copy to permit the bro 9 i 325 etirity.

\title{
RADIATION FIELD ASSOCIATED WITH \\ HIROSHIMA AND NAGASAKI
}

\section{FREPRINT}

\author{
Willam E. Loewe
}

lawrence Livermore National Laboratory

Prepared for

Presentation as an Invited Paper

at the

5tin ASTM-EURATOM Symposium on Reactor Dosimetry

GKisS Geesthacht, FRG

September $24-28,1984$

\section{August 1984}

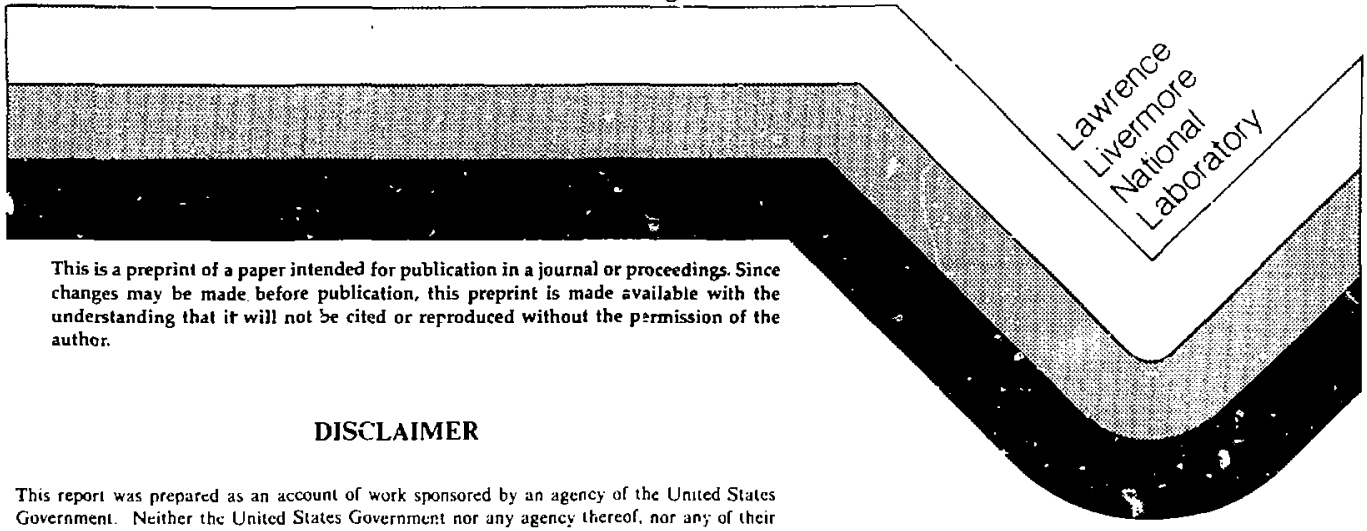
employes, makes any wanty, express or implied, or a a liability or respousibility for the acsuracy. completeress. or isefulness of any information, apparatus, product, ur process disclosed, or represents that its use would not infringe nrivately owned riphis. : sference herein to any specilic commercial product, process, or service by trade trame, trademark, manufactuter, of otherwise doss not necessarily constitute or imply its endorsement, recommendation, or favoring by the United States Government ar any agency thereof. The views and opinions of authors expressed herein do not nccessarily state or reflect those of the United States Governmen. or any agency thereof. 


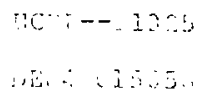

\title{
RADIATION FIELD ASSOCIATED WITH
}

\section{HIROSHIMA AND NAGASAKI*}

\author{
William E. Loewe \\ Lawrence Livermore National Laboretory \\ U.S.A.
}

\begin{abstract}
Accuracy of dosimetric eatimates can determine the value of the atcmic bomb gurvivor experience in establiabing radiation risks. The status of a major revision of thia dosimetry, initiated in 1980 , is assessed.
\end{abstract}

In 1980, dose levels to individual survivors at Hicoshima and Nagasakj were revised by factors as large as an order of magnitude, as shown in Figures $i$ and 2. (1) In those fjgures, T65D is the accepted designation for the old estimates. The most important changes shown there are cheracterized by an increase in total kerma of a factor of three at $2 \mathrm{~km}$ in Hiroshima, and a drop in the proportion of neutrons in the mixed field by a factor of fifteen at $1.5 \mathrm{~km}$, also in Hiroghima. Although the consequences are still unfolding, an immediate result of the new LLNL dosimetry was removal of A-bomb survivor support for large incraases in the neutron quality factor, as consilered formally by NCRF in 1980 .

In the ensuing years, a specially appointed commitiee of the U.S. National Academy of Sciences, chaired by Professor Frederick Seitz with Professor Robert Christy as primary consultant, has been studying the radiation field at Hiroshima and Nagasaki, in cooperation with a companion group in Japen. Ios Alamos National liaboratory (LANL) has made an improved estimate of radiation leakape

* Work performed under the auspi. is of the U.S. Department of Energy by the Lawrence Livermore National I-aboratory under Contract $H-7405-$ Eng-48. 
from the Little Boy bomb, which results in adjustment of the LiNL values in Figure 1 by $33 \%$ downward at all ranges for neutrors and by 6\% downwerd at all ranges for gamma rays. Oak Pidge National Trboratory (ORNL) as advanced alternative dosimetries, the most recer: of which confirmis these LLNL adjusted Figure 1 and Figure 2 values to roughly $+30 \%$ (after an outstanding controversy over the explosive yield at Hiroahima is discounted. This controversy, over whether the yield was $12.5 \mathrm{kt}$ or $15 \mathrm{kt}$, is still unresolved, but the present trend is toward agreement on the $15 \mathrm{kt}$ used in Figure 1.) To date, however, no alternative to the adjusted LLNL values has been offered which has not been shown subsequently to be in need of correction or is otherwise unsuitable to use as a replacement for those values as beat estimates. Therefore, comparisons in what follows will be made to tha Figure 1 and 2 values as reported in 1980 and elaborated in $1981(\mathrm{)})$, adjusted at Hiroshima to reflect the improved leakage eatimates as jist described ( $2 . e .$, reductiong of $33 \%$ and $6 \%$ ).

The ittie Boy bomb, which exploded 570 r. above Hirosinima at 0815 Augus: 6,1945 , generated $15 \mathrm{kt}$ from figsion of uranium assembled by a very large metal mechanism in a $E^{\prime \prime}$ arrangemert. The Fat Man bomb, exploded 503 m above Nagasaki at 1058 on August 3 , 1945, generated $22 \mathrm{kt}$, mostly flom plutonium assemblea by high explosive impiosion. Both bombs weighed four to five tons, of which the

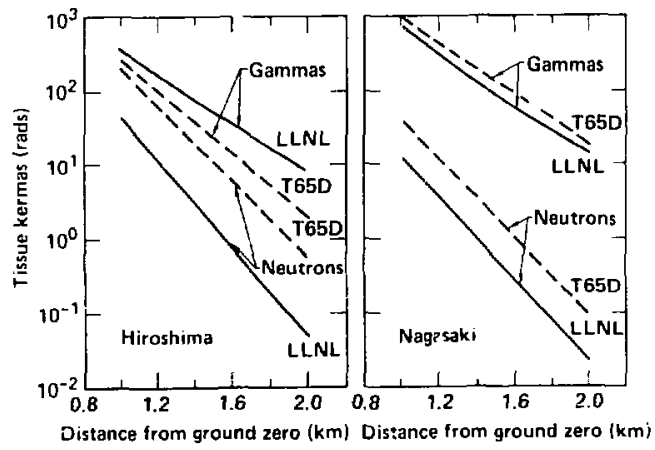

Figure 1. Free in-air tissue kermas at Hiroshima

Figure 2. Free-in air tissue kermas at Nagasaki

non-fissi ning assembly material constituted a thick blanket, surrounding the fissioning core. Neutrons and gamma rays generated in the core had to pass through this thick blanket to reach the atmosphere.

Although there are several reasons for the various errors in the old dosimetry aystem (T65D), the reason for the biggest error is the asaumption that neutrons which have passed through these two different blanket materials then penetrate the atmosplere equaljy well. 
Exiting neutrons, with kinetic energies in excess of about one-half $\mathrm{MeV}$ (which determine neutron dose beyond the $1 \mathrm{~km}$ grounc range where rost survivors were located) are actually distributed in energy as showr in Figure 3 . In this figure, various Little Boy spectra ere contrasted with the spectrum from a bare uranium metal reactor (normalized in intensity $s 0$ as to force agreement at 0.6 MeV for easy comparison). Although not shcwn here, the leakgge spectrum from the Fat Man bomb has a still larger proportion of higher energy neutrons (relative to those at one-half YeV) than a bare reactor, so that it is clear from Figure 3 that atmospheric penetration must be very different for the two combs, In fact, the resulting 30 difference $i r$ cose e-folding lengths can be thought of as generating the ifferences shown in the neutron curves for Hiroshima in Pigure?.

Figure 3 also compares (1) the ID calculationa at LANL uaed to generate Figure 1, (2) the more recent LANL calculations discussed previougly, and (3) measurements made by Robitaille and Hoffarth from Defence Research Establishment, Ottawa (DREO) at a replica of Little Boy prepsred and operated by LAVL as a reactor. Several other groups have confirmed the DREO cata shown in Figure 3 , including measurement teams led by Hoois and by Griffith at LLNL. These teams generated an improved description of the angular dependence of the spectra (resulting from the cylindrical symmetry of the gun assembly), and also measured neutron dose as a function of range to one-half kilometer. The two dose e-folding lengths cerived from these two independent sets of LLNL range data agree to six percent with my calculated value which is based on a recent adaptation of the calculation that generated Figure 1 values.

Static calculations by LANL in 1984, using tha same transport representetion as in the previous dynamic calculations, lie somewhat lower than the dynsmic results shown in Figure 3 and agree quite well with the measured data from DREO and from LLNL. Except for this modest dyramic effect, the little Boy leakage is now very well known.

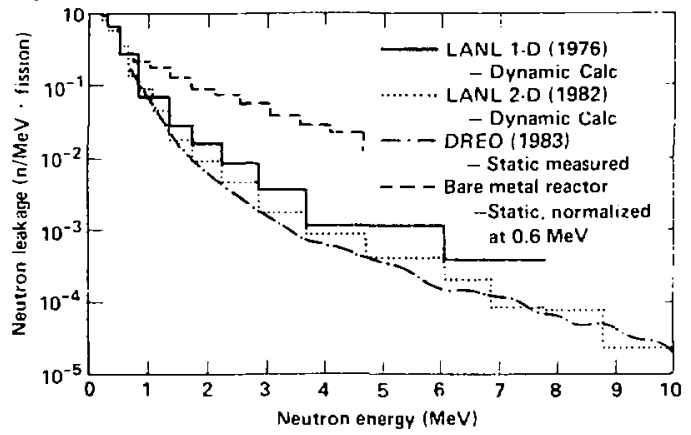

Figure 3. Little Boy neutron leakage energy spectra 
The accuracy of deep penetration, air-over-grcund radiation transport calculations, as used to generate Figyres 1 and 2 , has been established as betier than 25-30\% in kerma (2), but recent updates by DREO of certain measured values now give agreements as shown in Table I for a bare metal source, with spectral indications that this kind of agreement could be expected for Little Bny as well as for Fat Man sources.

\section{Table I}

\section{Bare Metal Reactor, LLNL Calc/Measurement}

Renge (km)

$$
\begin{array}{r}
.100 \\
.170 \\
.300 \\
.400 \\
1.080 \\
1.618
\end{array}
$$

\author{
Neutron Kerme
}

1.08

1.06

1.30

1.28

0.92

0.90
Gamine Ray Kerma
1.06
0.91
0.94
0.90
0.80
0.91

At least half of the somewhat larger neutron disagreements at $0.3 \mathrm{~km}$ and $0.4 \mathrm{~km}$ have been shown to be attributable to the effects of nea:by trees that were not modeled in the calculations. (Absolute accuracies of the date shown in Figures 1 and 2 are not as good due to uncertainties in source intensity and spectral composition, in meteorological conditions, and in terrain configuration and composition.)

One important difference in radiation intenuties between a nuclear reactor, as shown in Table $I$, and the explosions over Hiroshima and Nagasaki is due to atmospheric rearrangement by the blast wave, which permits delayed gamma rays emitted by fission fragments to contribute roughly half of the total dose even though their source strength is very small. The gamma ray data in Figures 1 and 2 include ir layed contributions as obtained from model of this dynamic phenomenology that is based on weapon field tests. The entire calculational chain used for Figures 1 and 2, including this delayed gamma ray model, was tested by comparing its estimetes witr: measured values from the Ranger Fox weapon field test, which was similar to the Nagagaki explogion. Agreement was within four percent at ground renges of $1.0 \mathrm{~km}$ and $1.8 \mathrm{~km}$, even though neither the measured nor the calculated estimates can claim such pccuracy. A similar dynamic enhancement of delayed fission reutrons also occurs, but I have recently shown this delayed neutron contributior. to be negligible, usiag the same model of the dynamic atmosphere. 
Thermoluminescence dosimetry in Hiroshime and Magasaki has recently been extended to ranges where most survivors were located, permitting comparisons with the gama ray data in Figures 1 and 2 . The comparisons shown in Figures 4 and 5 , which include earlier data at shorter ranges, show a striking confirmation of the essential correctness of the predicted values out to $1.5 \mathrm{~km}$. The abrupt jiscrepancies at 2.0 and $2.3 \mathrm{~km}$ at Nagasaki are thought to result from background contributions to the measurements at these great distarces.

Messurements of neutron activation of cobalt have recently veer. reported by Hashizume in Tokyo on samples exposed to the atmosprer on rcoftops in Hiroshima, as an extension of earlier measurements marie interior to concrete pillars. If a small adjustment, within tha Jimits of uncertainty, is made in the boron content of concrete (not measured at the time cobalt activation was measured inside pillars:. then the pillar and rooftop data form a consistent set to within 10-15\%. These data show calculations high by $15 \%$ compared to pxperiment near ground zero, low by $40 \%$ at one-half kilometer ground range, and lo: by a factor of four at one kilometer. This lack of agrement could be attributed to an unknown deficiency in source description due to dynamic effects during the explosion, an unknown deficiency in the celcilated transport of sub-kilovolt neutrons responsible for cobalt activation, or an unknown experimental problem. The same kind of dynamic source deficiency would have to apply to the very different Fat Man as to Little Boy, since the Nagasaki pillar comparinons parallel those at Hiroshima. Also, recent work by Woolson and Gritzner at Science Applications, Inc. (SAI) changes rair agreement of calculsted and measured values obtrined previously fo: sulfur activation into the excellent detailed agreement shown in Figure 6 .

Finglly, the attention brought by the 1980 revelation of nasor error in rree field kerma estimates allowed Jess Marcum of FDA to put forth improved estimates of the gamma ray shielding provided by Japanese dwellings. His factor of 1.6 , by which previous transintted gamma ray estimates are to be reduced, has been confirmed by SAI using detailed computer calculations that agree to log with selpeted velues measured at weapons tests inside model buildings. These salculations can be used to model in high detail any survivor shieliing contiguration for which geometry and material records are availahle.

In conclusion, large changes from the estimates discussed rero A $P$ increasingly unlikely. However, improvements are expected as $A$ result of the international program currently under way, and tho discrepancies noted in cobalt activation must be resolved. It is poss.tle that the absolute accuracy previously attributed to the Tot dosimetry, 30\%, might eventually be achieved for the new dosimctry.

I regret that only a few highlights could be included in this severely space-constrained overview, preventing ruference to many other important investigations. Howevor, George Kerr at ORN. has recertiy prepared an exhaustive bibliography for all of this wcrk. (3) 


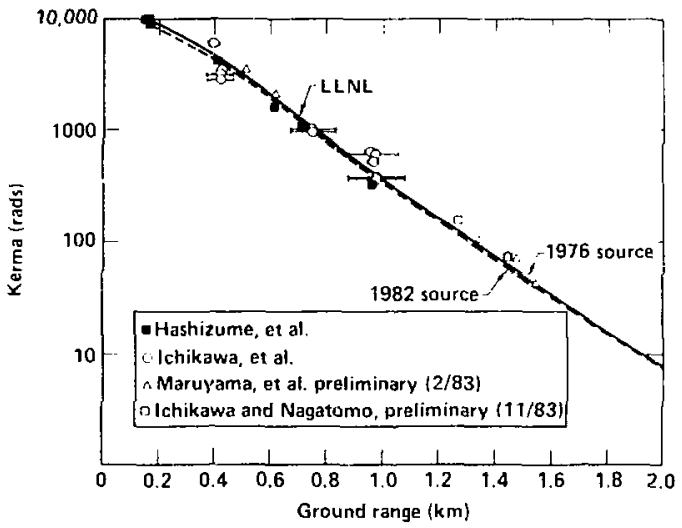

Figure 4. Gamma ray kermas ax Hiroshima

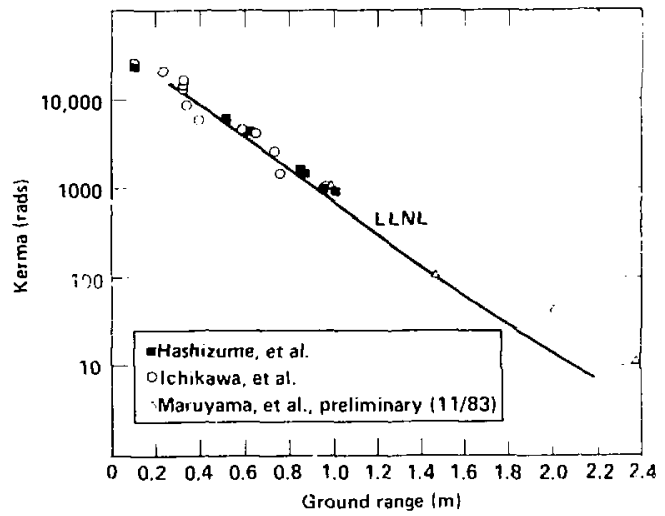

Figure 5. Gamma ray kermas at Nagasakı 


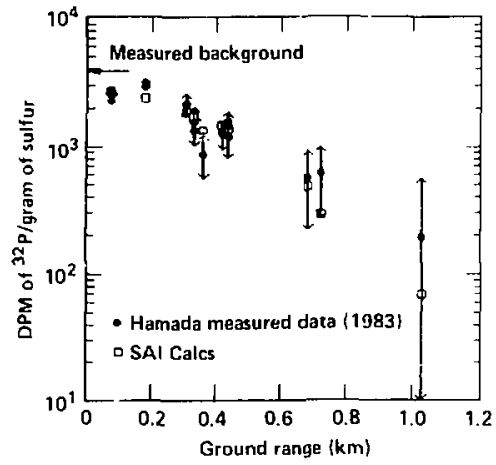

Figure 6. Sulfur activation comparison. Preliminary results by SAI

\section{REFERENCES}

2. H. E. Loewe and E. Mendelsohn, "Neutron and Gamma-Ray Doses at Hiroshima and Nagasaki", Nuc. Sci.\& Eng. 81, $325-350(1982)$.

2. H. E. Loewe, W. A. Turin, C. W. Pollock, A. C. Springer, and B. L. Richardson, "Validated Deep-Penetration, Air-Over-Ground, Neutron/Gamma-Ray Transport", Nuc. Sci.\& Eng. 85, 87-115 (1983).

3. G. D. Kerr, Bibliography of Literature Relevant to the Reassessment of A-Bomb hadiation Dosimetry in Hirosing and Nageaski; JRNL/TM-9138 (19844). 